\title{
Low angle light scattering analysis: a novel quantitative method for functional characterization of human and murine platelet receptors
}

\author{
Igor Mindukshev ${ }^{1,2, a}$, Stepan Gambaryan ${ }^{1,2, a}$, Linda \\ Kehrer $^{1}$, Claudia Schuetz ${ }^{1}$, Anna Kobsar ${ }^{1}$, Natalia \\ Rukoyatkina ${ }^{1,2}$, Viacheslav O. Nikolaev ${ }^{3}$, Alexander \\ Krivchenko $^{2}$, Steve P. Watson ${ }^{4}$, Ulrich Walter ${ }^{1, *}$ \\ and Joerg Geiger ${ }^{1, a}$ \\ ${ }^{1}$ Institute of Clinical Biochemistry and Pathobiochemistry, \\ University of Wuerzburg, Wuerzburg, Germany \\ ${ }^{2}$ Sechenov Institute of Evolutionary Physiology and \\ Biochemistry, Russian Academy of Sciences, St. Petersburg, \\ Russia \\ ${ }^{3}$ Emmy Noether Group of the DFG, Department of \\ Cardiology and Pneumology, Georg August University \\ Medical Center, Göttingen, Germany \\ ${ }^{4}$ Centre for Cardiovascular Sciences, Institute of Biomedical \\ Research, School of Clinical and Experimental Medicine, \\ College of Medical and Dental Sciences, University of \\ Birmingham, Birmingham, UK
}

\begin{abstract}
Background: Determinations of platelet receptor functions are indispensable diagnostic indicators of cardiovascular and hemostatic diseases including hereditary and acquired receptor defects and receptor responses to drugs. However, presently available techniques for assessing platelet function have some disadvantages, such as low sensitivity and the requirement of large sample sizes and unphysiologically high agonist concentrations. Our goal was to develop and initially characterize a new technique designed to quantitatively analyze platelet receptor activation and platelet function on the basis of measuring changes in low angle light scattering.

Methods: We developed a novel technique based on low angle light scattering registering changes in light scattering at a range of different angles in platelet suspensions during activation.

Results: The method proved to be highly sensitive for simultaneous real time detection of changes in size and shape of platelets during activation. Unlike commonly-used methods, the

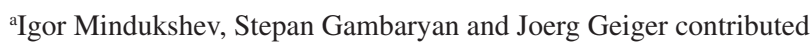
equally to this work.

*Corresponding author: Ulrich Walter, Institut für Klinische Biochemie and Pathobiochemie, Zentrallabor (IKBZ) Zentrum Innere Medizin Oberdürrbacher Str. 6, Haus A4 97080

Würzburg, Germany

Tel.: +49931 20145000, Fax: +49931201645000,

E-mail: uwalter@klin-biochem.uni-wuerzburg.de

Received May 25, 2011; accepted November 10, 2011;

previously published online December 8, 2011
\end{abstract}

light scattering method could detect platelet shape change and aggregation in response to nanomolar concentrations of extracellular nucleotides. Furthermore, our results demonstrate that the advantages of the light scattering method make it a choice method for platelet receptor monitoring and for investigation of both murine and human platelets in disease models.

Conclusions: Our data demonstrate the suitability and superiority of this new low angle light scattering method for comprehensive analyses of platelet receptors and functions. This highly sensitive, quantitative, and online detection of essential physiological, pathophysiological and pharmacological-response properties of human and mouse platelets is a significant improvement over conventional techniques.

Keywords: aggregation; platelet; $\mathrm{P} 2 \mathrm{X}_{1}$ receptor; $\mathrm{P} 2 \mathrm{Y}$ receptors.

\section{Introduction}

Platelet activation and aggregation play key roles in both normal hemostasis and pathological bleeding and thrombosis. Many bleeding and thrombosis disorders are most often associated with platelets dysfunctions (1-4). Exaggerated platelet aggregation response often leads to acute coronary syndromes, ischemic complications and stroke $(5,6)$. Therefore, monitoring of platelet activity is an important diagnostic parameter. Several different platelet function tests are widely used for monitoring platelet reactivity [for review see (7)]. However, the light-transmission aggregometry (LTA) as introduced by Born in 1963 (8) still serves as a gold-standard test for studies of platelet function and diagnostics of platelet disorders. Importantly, LTA and even other recently developed aggregometry tests have obvious limitations, such as low sensitivity, considerable sample consumption and the required unphysiologically high concentrations of stimulant. Since the introduction of LTA numerous attempts have been made to improve the sensitivity of this technique. These approaches, however, require a complex setup and/or sophisticated analysis and have not been fully established as functional platelet tests $(9,10)$. A considerable improvement has been achieved by switching from detection by light transmittance to an electrical detection by measuring the impedance of the sample (11). Even these novel techniques are still hampered by the clearly unphysiologically high concentration of stimulants required to achieve platelet aggregation and by their inability to detect platelet shape changes.

Here, we present a new method which is based on measuring changes in small angle light scattering of platelet suspensions 
during the aggregation process (Low angle Scattering method - LaSca). This method is characterized by high sensitivity and the ability to discern the aggregation process from platelet shape change in a single experiment. The presented method demonstrates a significantly improved sensitivity of light scattering over LTA with respect to stimulant concentration. For example, the ADP concentrations required here for stimulation of aggregation are one to two orders of magnitude lower than typically applied in LTA. Thus, this technique provides an outstanding improvement in platelet aggregometry and can be expected to advance platelet function diagnostics. Furthermore, not only platelet aggregation but all kinds of transitions of cellular shape in cell suspensions can be easily monitored by this method.

\section{Materials and methods}

An expanded Methods section is available in the Online Data Supplement.

\section{Preparation of human and mouse platelet rich plasma (PRP)}

Blood was obtained from healthy volunteers, clopidogrel treated, and Glanzmann patients after informed consent according to our Institutional Guidelines and the Declaration of Helsinki. Our studies with human platelets are approved and recently (24 September 2008) reconfirmed by the Local Ethics Committee of the University of Würzburg (Studies No. 67/92 and 114/04). Clopidogrel effects were investigated with blood from a health volunteer taking one bolus dose of $600 \mathrm{mg}$ clopidogrel. Volunteers and platelet inhibitor treated individuals were selected as previously described (12). The Glanzmann patient, aged 62 years, showed severe bleedings and was diagnosed Glanzmann's thrombasthenia type I. Platelet aggregation was absent in response to all agonists except ristocetin and flow cytometry analysis showed complete lack of GPIIb on the platelet surface and fibrinogen binding in response to platelet stimulation being absent. Mouse experiments were conducted in accordance with the German legislation on protection of animals and approved by the local animal care committee and governmental authorities. Human platelet rich plasma (PRP) was prepared as described previously (13) with minor modifications. Blood was collected into acid-citrate-dextrose anticoagulant (ACD, $12 \mathrm{mM}$ citric acid, $15 \mathrm{mM}$ sodium citrate, $25 \mathrm{mM}$ D-glucose, final concentrations) and $1 \mathrm{mM}$ EGTA and $0.2 \mathrm{U} / \mathrm{mL}$ apyrase (final concentration) was added directly to the whole blood sample. PRP was obtained by 15 min centrifugation at $330 \mathrm{~g}$. An appropriate amount of PRP was added to the buffer to achieve a density of 10,000 platelets $/ \mu \mathrm{L}$ (see Supplementary Figure 1). Mouse PRP was prepared according to published protocols (14). Briefly, blood was collected from the orbital sinus of mice anesthetized by ether inhalation into 1/7 volume of ACD. 1 mM EGTA and 0.2 $\mathrm{U} / \mathrm{mL}$ apyrase (final concentration) was added directly to the whole blood sample. Blood was centrifuged at $300 \mathrm{~g}$ for $5 \mathrm{~min}$ and PRP was centrifuged for additional $8 \mathrm{~min}$ at $80 \mathrm{~g}$ to separate from contaminating erythrocytes.

\section{Platelet experiments on low angle scattering device}

All experiments were performed in $6 \mathrm{~mL}$ of modified HEPES buffer (pH 7.4, osmolarity $302 \mathrm{mOsm}$, containing $140 \mathrm{mM} \mathrm{NaCl}, 10 \mathrm{mM}$ HEPES, $10 \mathrm{mM} \mathrm{NaHCO}_{3}, 2 \mathrm{mM} \mathrm{KCl}, 1 \mathrm{mM} \mathrm{MgCl}, 2 \mathrm{mM} \mathrm{CaCl}_{2}$,
5.5 mM D-glucose). An appropriate amount of PRP was added to the buffer to achieve a density of 10,000 platelets/ $\mu \mathrm{L}$ (see Supplementary Figure 1). After 2 min of establishing a constant basal signal, ADP, ATP, collagen or U46619 were added at indicated concentration to the platelet suspension. Inhibitors (AR-C69931, MRS2179, NF449, SQ-29548) were added 2 min prior to stimulation, and the recordings were performed during additional $10 \mathrm{~min}$. In control experiments without stimulation, the basal signal remained constant during this time interval.

\section{Data analysis}

All experiments were performed at least at $\mathrm{n}=4$, and summary data are expressed as means \pm SEM. Differences between groups were analyzed by ANOVA followed by Bonferroni's test and Student's $\mathrm{t}$-test was used when appropriate. $\mathrm{p}<0.05$ was considered statistically significant.

\section{Results}

\section{General principles and characterization of low angle Light scattering (LaSca) method}

The LaSca method is based on measuring the light scattering profile of a sample. The intensity profile of scattered light depends on the scatter angle and correlates with the size and shape of the observed particles. Therefore, it can be applied to quantify the distribution of size and shape of the particles present in suspension. The setup used here provides a simultaneous observation of the intensity of the scattered light at angles ranging from $1^{\circ}$ to $12^{\circ}$ (Supplementary Figure 2). During the aggregation process, platelets first undergo a change from an oblate spheroidal shape to a spherical shape and then to a complex shape characterized by cell protrusions linking the cells to a microaggregate, and, in a later step, to a macroscopic clot. Born aggregometry (LTA) is based on the principle of multiple scattering (15), hence the aggregation process is observed as a decrease in the amount of scattering particles but is not related to changes in particle size. By providing conditions of single scattering according to the Mie description of the scatter process, the LaSca technique allows for a simultaneous measurement of changes of particle size and shape. To maintain single scattering conditions, the platelet density must be adjusted to yield a transmittance of at least $50 \%$ of the transmittance of the cuvette alone (16). (For details see Online Data Supplement and Supplementary Figure 1).

To establish and verify this novel method, we used ADP, collagen and U46619 to induce platelet aggregation. The relation of light transmission (LT) to the light intensity of the scattered light (LSI) at $1^{\circ} \mathrm{I}(1)$ in dependence on platelet concentration, was determined with the setup to provide data on the range of an adequate platelet density. The maximum platelet density allowing single light scattering measurements was determined to be 10,000 platelets $/ \mu \mathrm{L}$, therefore PRP used in the experiments was diluted with buffer accordingly (Supplementary Figure 1).

For verification of the underlying theory a model for the platelet aggregation processes was established using three different stages representing the isolated platelet 
(monomeric-particle), platelet dimers (dimeric particle) and a mixture of dimers and larger aggregates (multimeric particles) (Supplementary Figure 3A). We calculated angle diagrams for all these stages (Supplementary Figure 3B). More detailed calculation of these parameters is presented in the Online Data Supplement. The angle dependent scatter intensity curve of the monomeric particle intersects the curve for dimers at a scatter angle of $7^{\circ}$, and the curve for the mixture of multimers at $5.5^{\circ}$. The calculated model predicts an increase of scatter intensity between $1^{\circ}$ and $5.5^{\circ}$, while between $7^{\circ}$ and $12^{\circ}$ a decrease should be observed. The model predictions were experimentally tested for the aggregation of human platelet suspensions (Supplementary Figure 3C). Angle dependent scatter intensities were measured in a range from $1^{\circ}$ to $12^{\circ}$ using human platelet suspensions stimulated with $0.6 \mu \mathrm{M}$ ADP. The experimental data were in good accordance with the calculated scatter curves (compare Supplementary Figure 3B and 3C). As predicted by the model (Supplementary Figure 3A), the intensity of the scattered light increased between $1^{\circ}$ and $5^{\circ}$ and decreased between $9^{\circ}$ and $12^{\circ}$ (Figure 1A, 1B) during ADP stimulated platelet aggregation. In the range between $5^{\circ}$ and $8^{\circ}$ the changes in scatter intensity were less pronounced and are thus not suited for aggregation measurements. From the scatter curves shown in Figure $1 \mathrm{~A}$ it is evident that changes in scatter intensity are maximal at $1^{\circ}$, making this angle particularly suitable for aggregation measurement. Platelet shape dependent changes in scatter intensity are not observed at $1^{\circ}$. This phenomenon is reflected by an increase of scatter intensity at $8^{\circ}-12^{\circ}$ with a maximal change at $12^{\circ}$ (Figure 1A, 1C). Consequently, we chose a scatter angle of $1^{\circ}$ to measure platelet aggregation and $12^{\circ}$ for monitoring of platelet shape change. ADP stimulated a concentration-dependent increase of aggregation velocity and amplitude with a maximum response at $1 \mu \mathrm{M}$ of ADP (Figure 1B). Maximal shape change was induced by $90 \mathrm{nM}$ ADP, a concentration which is not sufficient to induce platelet aggregation (Figure 1C). We next characterized platelets from a Glanzmann's thrombasthenia patient who showed no platelet aggregation, while under the same conditions platelets from healthy volunteers fully aggregated. This served as additional proof that the data from the scatter angle of $1^{\circ}$ represents platelet aggregation (Supplementary Figure 4).

\section{Quantitative characterization of platelet P2 receptors by LaSca method}

Platelet receptors for extracellular nucleotides (ADP, ATP) belong to the $\mathrm{P} 2$ family and consist of two classes of membrane receptors: $\mathrm{G}$ protein-coupled $\mathrm{P} 2 \mathrm{Y}_{1}$ and $\mathrm{P} 2 \mathrm{Y}_{12}$, and ligand-gated cation channel $\mathrm{P} 2 \mathrm{X}_{1}$ receptors (17-20). We applied our method to registration of platelet shape change and aggregation and for quantitative characterization of P2 receptors using established specific inhibitors. Platelet aggregation can be analyzed by measurement of the initial velocity $\left(\mathrm{V}_{\mathrm{ia}}\right)$ of aggregation during the first 60s interval after stimulation and the maximal amplitude $[\Delta \mathrm{I}(1)]$, calculated as differences between the maximal scatter intensity and the initial scatter intensity prior to stimulation. Both values are strongly
A
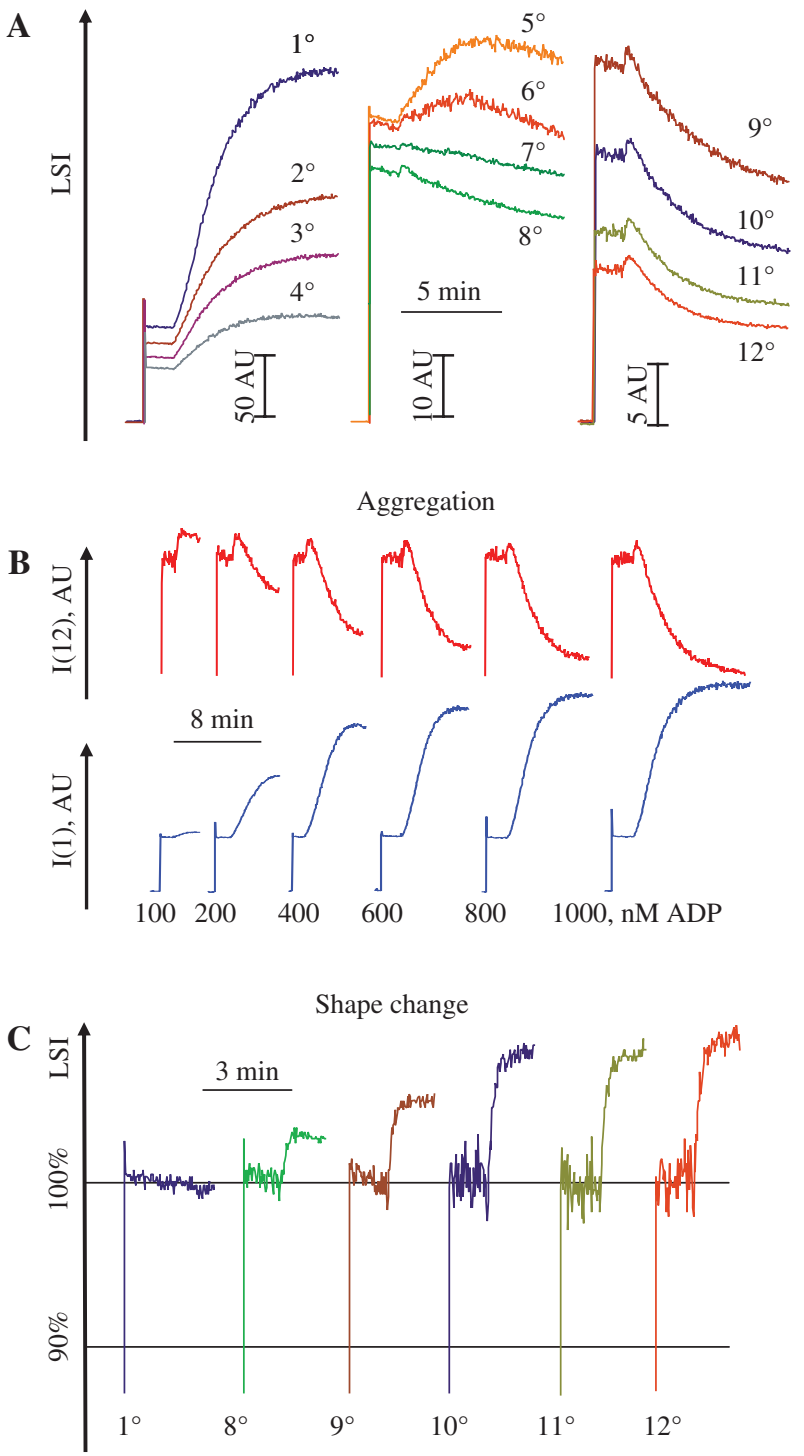

Figure 1 Application of low angle light scattering method for measuring platelet aggregation and shape change.

Light scatter intensity (LSI) measured at 12 different scatter angles in ADP (500 nM) stimulated human platelet suspension. For better resolution the ordinate scale is enlarged 5 times for the $5^{\circ}-8^{\circ}$ curves and 10 times for the $9^{\circ}-12^{\circ}$ curves. According to the predicted changes in LSI (see Supplementary Figure 3), during aggregation the LSI increases in the range of $1^{\circ}-5^{\circ}$ and decreases in the range of $8^{\circ}-12^{\circ}$. (B) Original recording of LSI measured at $1^{\circ}$ and $12^{\circ}$ of ADP stimulated human platelets with the concentrations indicated. I(1) and I(12) correspond to LSI at $1^{\circ}$ or $12^{\circ}$. (C) Characterization of platelet shape change by LSI. LSI presented as $\%$ increase from basal $(100 \%)$ measured at seven different scatter angles with ADP $(90 \mathrm{nM})$ stimulated human platelet suspension. The maximal increase in LSI is observed at $12^{\circ}$.

$\left(\mathrm{R}^{2}=0.93\right)$ correlated (Figure $\left.2 \mathrm{~A}\right)$. Verification of the observations with the light scattering method was also accomplished with measurements of established platelet activation markers like P-selectin expression and activated integrin $\alpha 2 b \beta 3$ in flow cytometry. These data show a good correlation of light 
A

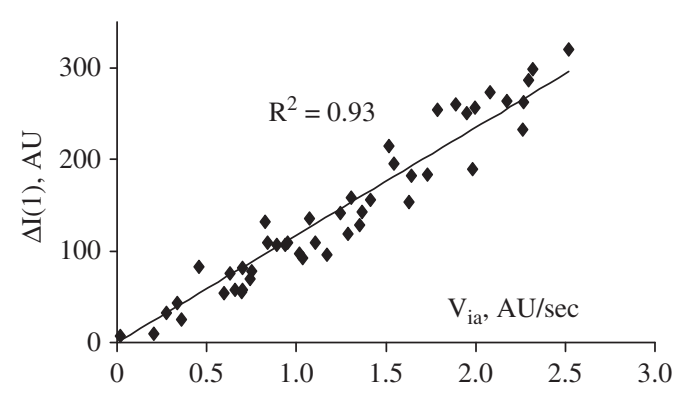

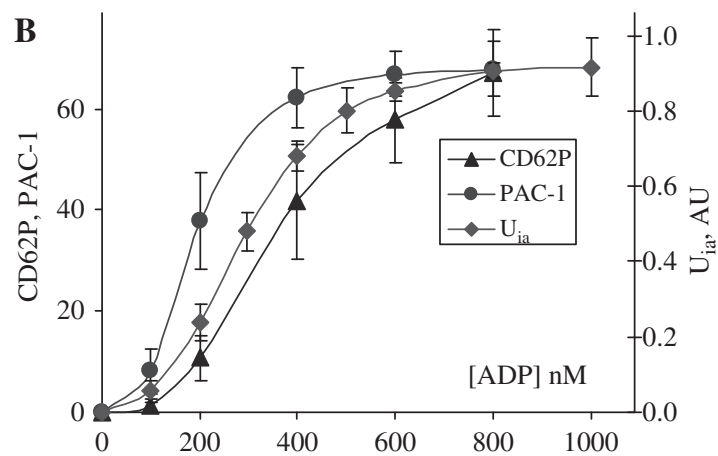

C
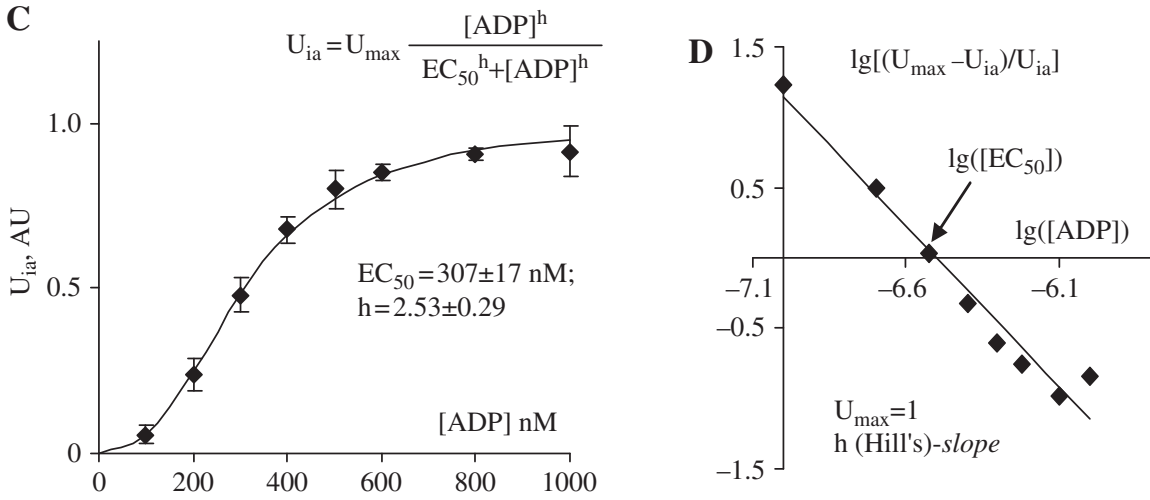

Figure 2 Characterization of ADP-induced human platelet aggregation.

Diluted human PRP was analyzed by the light scattering method for ADP-induced platelet aggregation. (A) Correlation between initial velocity of aggregation $\left(\mathrm{V}_{\mathrm{ia}}, \mathrm{AU} / \mathrm{s}\right)$ and maximal increase of light scattering intensity which corresponds to the maximal amplitude of aggregation at $1^{\circ}$ from the basal signal level, $(\Delta \mathrm{I}(1), \mathrm{AU})$. (B) Dependence of platelet activation [flow cytometry analysis of platelet P-selectin (CD62P) surface exposure and $\alpha 2 \mathrm{~b} \beta 3$ integrin activation (PAC-1 binding)] and initial velocity $\left(\mathrm{U}_{\mathrm{ia}}\right)$ of aggregation from ADP concentrations. LSI is given in arbitrary units (AU) of the intensity of the scattered light. Flow cytometry data presented as mean fluorescence. For flow cytometry analysis platelets were taken directly from the cuvette 2 min after stimulation. (C) Dependence of normalized initial velocity $\left(\mathrm{U}_{\mathrm{ia}}\right)$ of aggregation on ADP concentrations. Data are mean $\pm \operatorname{SEM}(n=32)$, continuous lines represent fits of the Hill equation to the experimental data $\left(\mathrm{EC}_{50}=307 \pm 17\right.$ $\mathrm{nM}, \mathrm{h}=2.53 \pm 0.29)$. $\mathrm{U}_{\max }$, normalized maximal velocity of aggregation; h, Hill coefficient. (D) Schild plot for calculations of $\mathrm{EC}_{50}$ and Hill coefficient (h) used in the Figure C.

scatter intensity results with changes in established platelet activation markers (Figure 2B, Supplementary Figure 5). The aggregation velocity was used as an important parameter for further pharmacological experiments. The maximal aggregation velocity $\left(\mathrm{V}_{\max }\right)$ was calculated for each experiment. To directly compare the results obtained in different experiments, we calculated the relative initial aggregation velocity designated as $\mathrm{U}_{\mathrm{ia}}$ as according to the equation $\mathrm{U}_{\mathrm{ia}}=\mathrm{V}_{\mathrm{ia}}$ ' $\mathrm{V}_{\max }$, and determined the normalized maximal aggregation velocity $\left(\mathrm{U}_{\max }\right)$ The normalized initial aggregation velocity $\mathrm{U}_{\mathrm{ia}}$, according to the Hill equation, showed the expected sigmoid concentration-response dependence from ADP concentrations (Figure 2C). The parameters for this equation were obtained from a Schild plot (Figure 2D). The value for the Hill coefficient $(2.53 \pm 0.29)$ reflects the observed cooperativity of $\mathrm{P} 2 \mathrm{Y}_{1}$ and $\mathrm{P} 2 \mathrm{Y}_{12}$ receptor activation in platelets (19). ADP is routinely used in platelet aggregation tests in clinical laboratories over the range 3-10 $\mu \mathrm{M}$. The $\mathrm{EC}_{50}$ for ADP-induced platelet aggregation calculated from our data was $307 \pm 17$ $\mathrm{nM}$ with a maximal response at $1 \mu \mathrm{M}$ (Figure $2 \mathrm{C}$, Table 1 ). Inhibition of the $\mathrm{P} 2 \mathrm{Y}_{1}$ receptor significantly increased the
$\mathrm{EC}_{50}$ for ADP without affecting $\mathrm{U}_{\max }$ (Figure 3A, Table 1). In contrast, $\mathrm{P} 2 \mathrm{Y}_{12}$ inhibition significantly decreased $\mathrm{U}_{\max }$ leaving the $\mathrm{EC}_{50}$ unchanged (Figure 3B, Table 1). These data support the hypothesized function of the $\mathrm{P} 2 \mathrm{Y}_{1}$ receptor as being necessary for the initiation of platelet aggregation, and the $\mathrm{P}_{2} \mathrm{Y}_{12}$ receptor for maintenance of aggregation (21). However, as described for $\mathrm{P}_{2} \mathrm{Y}_{1}(22,23)$ and $\mathrm{P}_{2} \mathrm{Y}_{12}(24)$ knockout mouse models, the lack of either receptor does still allow for a small aggregation response. In line with this model, we obtained similar results in light scatter experiments (Supplementary Figure 6).

\section{Registration of platelet shape change by LaSca method}

Platelet shape change is a reversible process which involves cytoskeleton reorganization resulting in a transition from discoid to spherical shape and then to a complex shape characterized by cell protrusions. Shape change reaction is mediated by two receptors, $\mathrm{P} 2 \mathrm{Y}_{1}$ which is activated by ADP and P2X $\mathrm{X}_{1}$ activated by $\operatorname{ATP}(25,26)$. In our experiments, 
Table 1 Calculated values of maximal velocity of platelet aggregation $\left(\mathrm{U}_{\max }\right), \mathrm{EC}_{50}$, and Hill coefficient (h) for ADP and collagen alone induced platelet aggregation and in the presence of $\mathrm{P}_{1} \mathrm{Y}_{1}$ (MRC2179), P2Y $\mathrm{Y}_{12}$ (AR-C69931) and TXA 2 (SQ-29548) receptors inhibitors.

\begin{tabular}{|c|c|c|c|c|}
\hline Stimulation $^{\circ}$ & $\mathrm{U}_{\max }$ & $\begin{array}{l}\mathrm{EC}_{50}(\mathrm{ADP}, \mathrm{nM}) \\
(\text { Collagen, } \mu \mathrm{g} / \mathrm{mL})\end{array}$ & $\mathrm{h}$ & $\mathrm{n}$ \\
\hline ADP & $1.00 \pm 0.15$ & $307 \pm 17$ & $2.5 \pm 0.3$ & 32 \\
\hline +MRS $100 \mathrm{nM}$ & $1.00 \pm 0.09$ & $434 \pm 28^{a}$ & $3.1 \pm 0.9$ & 4 \\
\hline +MRS 400 nM & $1.00 \pm 0.16$ & $668 \pm 97^{a}$ & $3.8 \pm 0.5^{\mathrm{a}}$ & 6 \\
\hline +MRS $1000 \mathrm{nM}$ & $1.00 \pm 0.09$ & $781 \pm 60^{\mathrm{a}}$ & $3.6 \pm 0.4^{\mathrm{a}}$ & 6 \\
\hline +ARC $0.5 \mathrm{nM}$ & $1.00 \pm 0.18$ & $368 \pm 83$ & $3.1 \pm 0.3$ & 4 \\
\hline +ARC $1 \mathrm{nM}$ & $0.81 \pm 0.21$ & $377 \pm 32$ & $3.1 \pm 0.6$ & 6 \\
\hline +ARC $10 \mathrm{nM}$ & $0.38 \pm 0.14^{\mathrm{a}}$ & $424 \pm 76^{\mathrm{a}}$ & $3.1 \pm 0.2$ & 6 \\
\hline Collagen & $1.00 \pm 0.06$ & $3.29 \pm 0.14$ & $2.6 \pm 0.3$ & 26 \\
\hline$+\mathrm{MRS} 1 \mu \mathrm{M}$ & $1.00 \pm 0.09$ & $5.21 \pm 0.22^{\mathrm{a}}$ & $2.2 \pm 0.4$ & 6 \\
\hline +ARC $20 \mathrm{nM}$ & $1.00 \pm 0.11$ & $4.72 \pm 0.27^{\mathrm{a}}$ & $2.7 \pm 0.6$ & 4 \\
\hline +SQ $1 \mu \mathrm{M}$ & $0.60 \pm 0.09^{\mathrm{a}}$ & $3.37 \pm 0.17$ & $2.3 \pm 0.5$ & 4 \\
\hline +MRS+ARC & $0.35 \pm 0.06^{\mathrm{a}}$ & $3.21 \pm 0.11$ & $3.5 \pm 0.4^{\mathrm{a}}$ & 6 \\
\hline +MRS+ARC+SQ & $0.19 \pm 0.03^{\mathrm{a}}$ & $3.16 \pm 0.25$ & $4.1 \pm 0.7^{\mathrm{a}}$ & 6 \\
\hline
\end{tabular}

The values were calculated according to the experimental data presented in the Figures $3 \mathrm{~A}, 3 \mathrm{~B}$ and $5 \mathrm{C}$. Data are presented as mean \pm SEM, ${ }^{a} \mathrm{p}<0.05$ compared with ADP or collagen alone, respectively.

$\mathrm{EC}_{50}$ for platelet shape change for ADP was $47 \pm 7 \mathrm{nM}$ with a maximal response at $90 \mathrm{nM}$ (Figure 4A, 4C). This ADP response could be completely blocked by the specific $\mathrm{P} 2 \mathrm{Y}_{1}$ receptor antagonist (MRS2179), without any effects of $\mathrm{P}_{2} \mathrm{Y}_{12}$ (AR-C69931) and P2X (NF449) receptor antagonists (Figure 4C). ADP stimulation of shape change can be described by the Langmuir equation with Hill coefficient 1.1 \pm 0.3 (Figure $3 \mathrm{~A})$. The $\mathrm{P} 2 \mathrm{X}_{1}$ receptor is a well characterized non-selective ligand gated cation channel activated by extracellular ATP. Activation of the platelet $\mathrm{P} 2 \mathrm{X}_{1}$ receptor leads to a transient increase of intracellular calcium and reversible shape change (27). The $\mathrm{EC}_{50}$ for the non-hydrolyzable ATP analog $(\alpha, \beta$ meATP) measured by calcium influx mediated by $\mathrm{P} 2 \mathrm{X}_{1}$ receptor was estimated to be approximately $0.4 \mu \mathrm{M}(28,29)$, while the $\mathrm{EC}_{50}$ for this receptor expressed in oocytes was in nanomolar range (30). In other recombinant and native $\mathrm{P} 2 \mathrm{X}_{1}$ expression systems, the $\mathrm{EC}_{50}$ for ATP is approximately $1 \mu \mathrm{M}$ (31). Here, we directly show $\mathrm{P} 2 \mathrm{X}_{1}$ receptor mediated activation of platelet shape change by ATP with an $\mathrm{EC}_{50} 23 \pm 4 \mathrm{nM}$ and a maximal effect at $50 \mathrm{nM}$ (Figure 4B, 4D). Importantly, our data for the first time allow the quantitative characterization of directly measured $\mathrm{P} 2 \mathrm{Y}_{1}$ and $\mathrm{P} 2 \mathrm{X}_{1}$ receptor-mediated platelet shape change.

\section{Importance of secreted ADP, ATP and thromboxane $A_{2}\left(T \times A_{2}\right)$ for collagen-induced platelet aggregation}

Platelets activated by strong stimuli like collagen, thrombin or von Willebrand factor (vWF) release soluble platelet agonists (ADP, ATP) and produce TxA $\mathrm{A}_{2}$ which play an important role in formation of firm platelet aggregates. Since the LaSca method requires highly diluted PRP to achieve single scattering, we checked whether the influence of secreted ADP
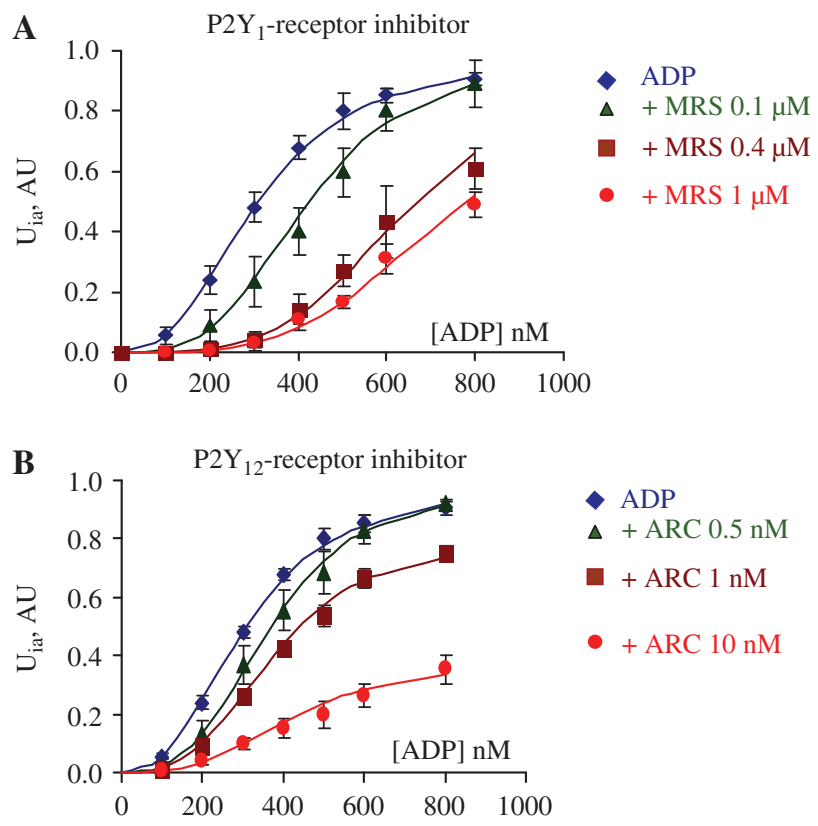

Figure 3 Quantitative characterization of P2Y-receptor-induced platelet aggregation.

Human platelet responses to ADP were analyzed by the light scattering method for aggregation. Dependence of the initial velocity $\left(\mathrm{U}_{\mathrm{ia}}\right)$ of aggregation from ADP concentrations (ADP) and in presence of indicated concentrations of a $\mathrm{P}_{2} \mathrm{Y}_{1}$ receptor inhibitor (+MRS2179) (A) and a P2Y $\mathrm{Y}_{12}$ receptor inhibitor (+AR-C69931) (B). Data are means \pm SEM, continuous lines represent fits of the Hill equation to the data presented in Table $1\left(\mathrm{U}_{\max }, \mathrm{EC}_{50}, \mathrm{~h}\right)$. Inhibition of the P2Y receptor significantly increases $\mathrm{EC}_{50}$, without changing of $\mathrm{U}_{\max }$, while inhibition of the $\mathrm{P} 2 \mathrm{Y}_{12}$ receptor significantly decreases $\mathrm{U}_{\max }$.

and $\operatorname{TxA}_{2}$ on platelet aggregation is observable under these conditions. We used the established ADP receptors inhibitors (AR-C69931, MRS2179) which are specific for the $\mathrm{P}_{2} \mathrm{Y}_{12}$ and $\mathrm{P}_{2} \mathrm{Y}_{1}$ receptor, respectively (Figures 2 and 3), and SQ-29548 for the inhibition of the TP $\left(\mathrm{TxA}_{2}\right)$ receptor. The stable TxA analog U-46619 induced platelet shape change and strong activation at $100 \mathrm{nM}$ which was completely inhibited by preincubation with $1 \mu \mathrm{M}$ of SQ-29548 (Figure 5A). The $\mathrm{EC}_{50}$ for collagen induced platelet aggregation was $3.29 \pm 0.14 \mathrm{ng} / \mathrm{mL}$ with a Hill coefficient of $2.6 \pm 0.3$ (Table 1). Preincubation of platelets with $\mathrm{P} 2 \mathrm{Y}$ and TP receptor inhibitors strongly reduced collagen-induced shape change and aggregation (Figure 5B, $5 \mathrm{C}$, Table 1) indicating that our method is capable of detecting the effects of soluble agonist secreted from activated platelets.

\section{Application of the LaSca method for analysis of mouse platelets}

Transgenic mouse models are widely used for investigation of platelet function, therefore any novel technique for platelet function analysis should be applicable to mouse platelets. To achieve comparable aggregation, mouse platelets require higher ADP concentrations than human platelets (22). In our experimental settings, the $\mathrm{EC}_{50}$ for $\mathrm{ADP}$ of mouse platelets 

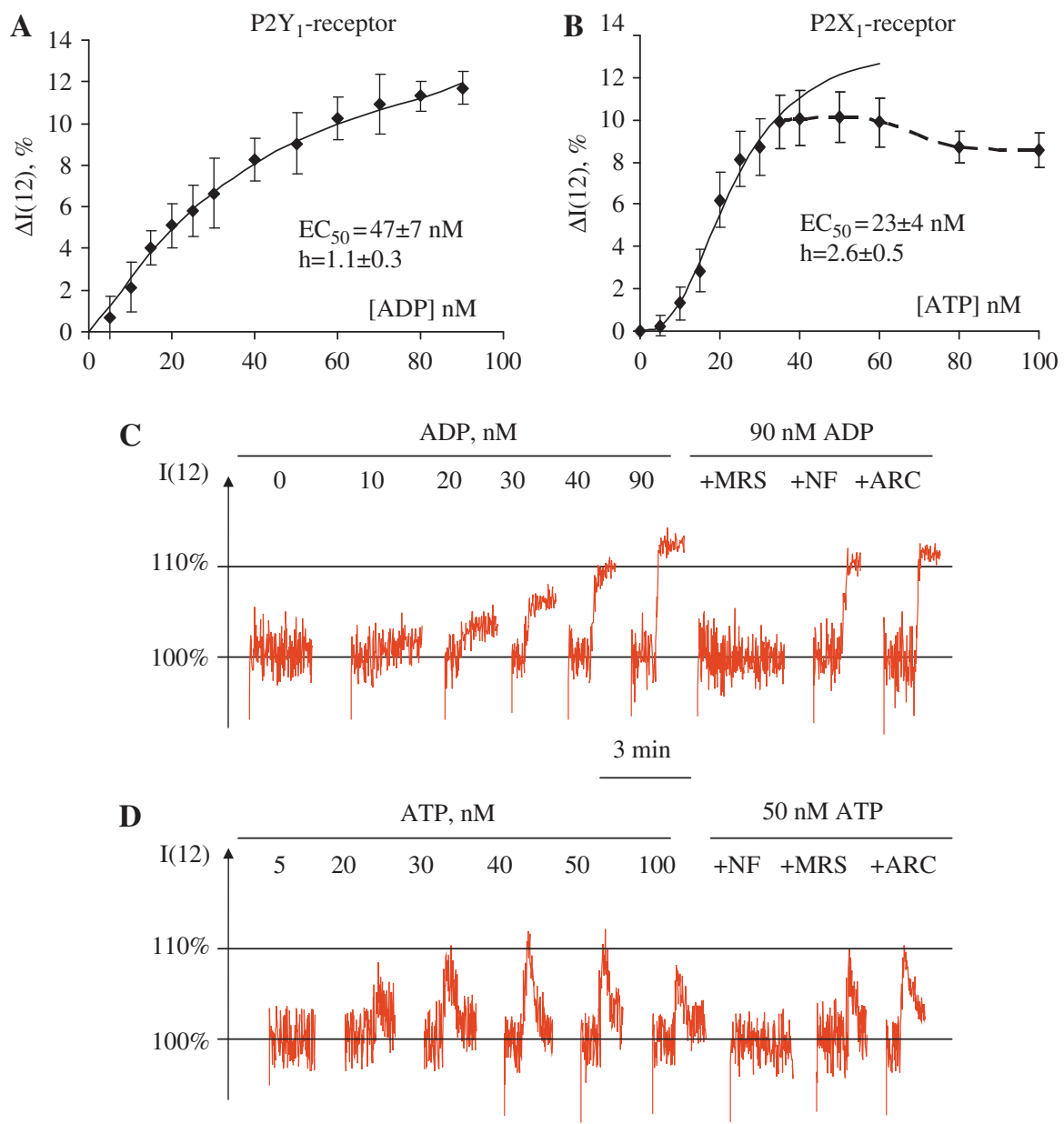

Figure 4 Quantitative characterization of $\mathrm{P}_{2} \mathrm{Y}_{1}$ and $\mathrm{P} 2 \mathrm{X}_{1}$-receptor-induced platelet shape change.

Diluted human PRP was analyzed by the light scattering method at $12^{\circ}$ for indicated concentrations of ADP (A) and ATP (B) induced shape change calculated as $\%$ increase of LSI at $12^{\circ}[\Delta \mathrm{I}(12), \%]$ from the basal signal level taken as $100 \%$. Original recordings (representative for five independent experiments) of dose-response effects of human platelets to ADP (C) and ATP (D) induced shape change. $90 \mathrm{nM}$ ADP induces a maximal shape change reaction without initiating of an aggregation response and can be completely blocked by a specific $\mathrm{P}_{2} \mathrm{Y}_{1}$ receptor inhibitor ( $2 \mu \mathrm{M}$ MRS2179). In contrast, inhibition of P2X $\mathrm{X}_{1}(2 \mu \mathrm{M}, \mathrm{NF} 449)$ and $\mathrm{P} 2 \mathrm{Y}_{12}$ (AR-C69931, $\left.20 \mathrm{nM}\right)$ receptors had no significant effects on ADP-induced shape change. ATP-induced shape change is more rapid and reversible, it could be inhibited only by a specific $\mathrm{P} 2 \mathrm{X}_{1}$ receptor inhibitor (NF449, $2 \mu \mathrm{M})$, whereas MRS2179 $(2 \mu \mathrm{M})$ and AR-C69931 (20 nM) had no effect. The P2Y, receptor response (A) can be described by the Langmuir equation $\left(\mathrm{EC}_{50}=54 \pm 7 \mathrm{nM}, \mathrm{h}=1.1 \pm 0.3\right.$ ), while the $\mathrm{P} 2 \mathrm{X}_{1}$ receptor $(\mathrm{B})$ response can be described by a sigmoid curve in a linear coordinate system and a Hill coefficient higher than unity $\left(\mathrm{EC}_{50}=18 \pm 4 \mathrm{nM}, \mathrm{h}=2.6 \pm 0.5\right)$. Data are mean $\pm \mathrm{SEM}, \mathrm{n}=8$.

was $350 \pm 21 \mathrm{nM}$ (Figure 6) which was slightly higher than for human platelets $(307 \pm 17 \mathrm{nM})$. However, maximal ADP response $(1 \mu \mathrm{M})$ was similar in human and mouse (compare Figures 2 and 6). Maximal shape change response induced by activation of $\mathrm{P}_{2} \mathrm{Y}_{1}\left(90 \mathrm{nM}\right.$ of ADP) and $\mathrm{P} 2 \mathrm{X}_{1}$ (50 $\mathrm{nM}$ of ATP) receptors were similar to human platelets (compare Figures 4 and 6). We also used other agonists (thrombin, collagen, $\mathrm{TxA}_{2}$ ) and obtained similar results for human and mouse platelet aggregation responses (data not shown).

\section{Application of the LaSca method for drug monitoring}

The potent aggregation inhibiting drug clopidogrel irreversibly blocks the platelet $\mathrm{P}_{2} \mathrm{Y}_{12}$ receptor. However, clinical experience indicates a remarkably high rate of therapy failure with clopidogrel which results primarily from insufficient metabolism of the prodrug. Since insufficient anti-platelet treatment bears an increased risk of fatal secondary cardiovascular events, timely detection of weak or absent response to the treatment is desired. In preliminary experiments, we analyzed PRP from a patient which normally responds to clopidogrel (Figure 7A, 7B) before (control) and after $6 \mathrm{~h}$ and $24 \mathrm{~h}$ of a single clopidogrel $(600 \mathrm{mg}$ ) dose (responder). We also analyzed PRP $24 \mathrm{~h}$ after the same dose of clopidogrel given to a clopidogrel non-responder (non-responder, Figure 7C, 7D). In the clopidogrel responder, the observed effect was similar to in vitro inhibition of the $\mathrm{P} 2 \mathrm{Y}_{12}$ receptor (compare Figures 7A and 3B). ADP-induced platelet aggregation parameters of the non-responder were similar to control (compare Figures $2 \mathrm{C}$ and $7 \mathrm{C}$ ). Inhibition of $\mathrm{P} 2 \mathrm{Y}_{12}$ receptor by 
A<smiles>C1CCCCC1</smiles>

I(1)

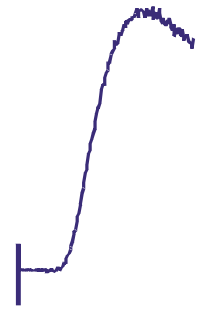

$3 \mathrm{~min}$

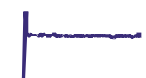

B
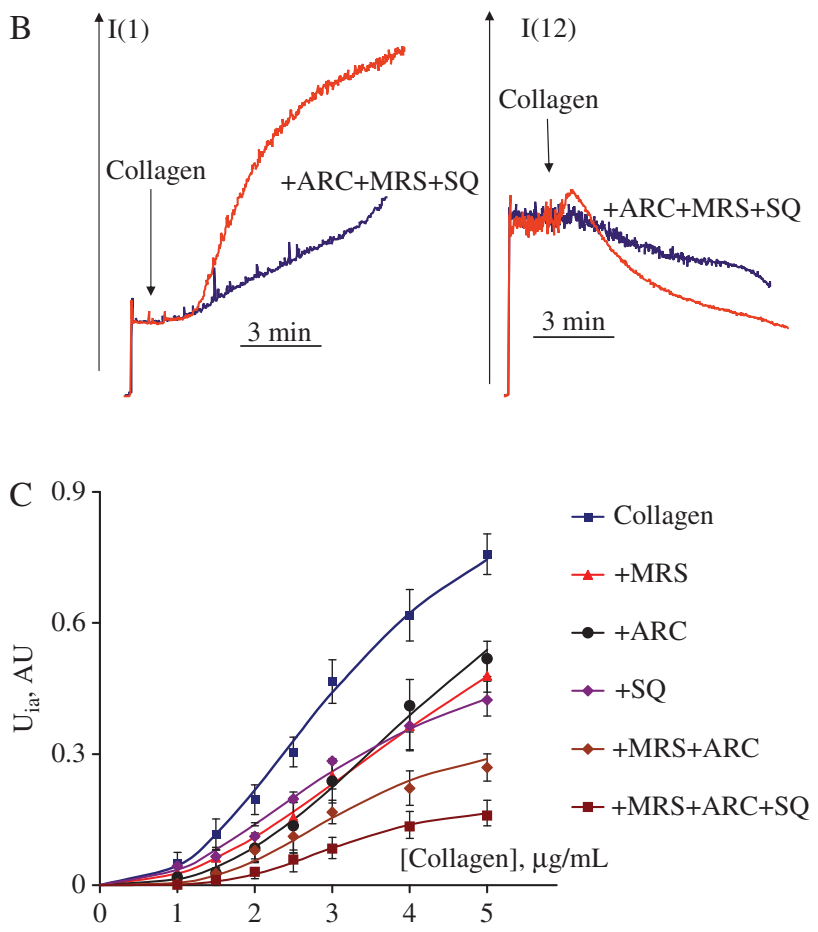

Figure 5 Secreted ADP and TXA 2 play an essential role in collagen induced platelet aggregation.

Diluted human PRP was analyzed by the light scattering method for U46619 and collagen-induced platelet aggregation. (A) Original recordings (representative for four independent experiments) of human platelet shape change I(12) and aggregation I(1) induced by $80 \mathrm{nM}$ of U46619. Preincubation ( $2 \mathrm{~min}$ ) with TXA2 receptor inhibitor (+1 $\mu \mathrm{M}$ SQ-29548) completely prevents platelet aggregation and shape change. (B) Original recordings (representative for four independent experiments) of human platelet shape change I(12) and aggregation $\mathrm{I}(1)$ induced by collagen $(5 \mu \mathrm{g} / \mathrm{mL})$ and in preincubation (2 min) with P2Y ${ }_{12}$ (10 nM AR-C69931), P2Y1 (1 $\mu$ M MRS2179), and TXA 2 (1 $\mu \mathrm{M}$ SQ-29548) receptor inhibitors. (C) Dependence of the initial velocity $\left(\mathrm{U}_{\mathrm{i}}\right)$ of aggregation from collagen concentration and in presence of $\mathrm{P}_{2} \mathrm{Y}_{12}, \mathrm{P} 2 \mathrm{Y} 1$, and TXA 2 receptor inhibitors. Data are means \pm SEM, continuous lines represent fits of the Hill equation to the data presented in Table $1\left(\mathrm{U}_{\max }, \mathrm{EC}_{50}, \mathrm{~h}\right)$.
AR-C69931 indicates that absence of reaction to clopidogrel was not connected with any abnormalities of the $\mathrm{P} 2 \mathrm{Y}_{12}$ receptor function.

\section{Discussion}

Laser particle size analyzers available from commercial sources (e.g., Malvern, Beckman, Horiba, Fritch, and others) are widely used for size distribution analysis of natural and artificial particles. However, up until now, these devices have not been routinely applied to biological systems. Based on the technology used in these analyzers we created a new device and developed original software for the registration of platelet aggregation and shape change.

Platelet aggregometry ("Born aggregometry", LTA) is recognized as a meaningful and valuable method for studying platelet function, and despite the availability of other methods, LTA is still regarded as the gold standard in platelet analysis. In LTA, changes in the transmittance of the sample are registered, its sensitivity is relatively low and only limited information about net changes in cell shape or volume can be obtained. Aggregometry is suitable for the detection of platelet functional defects and for monitoring of pharmacological properties of anti-platelet drugs. Platelet aggregation, however, as a general functional readout parameter does not allow for a detailed analysis of the underlying biochemistry as it results from a co-action of simultaneous or sequential processes, eventually leading to aggregate formation. In contrast, LaSca method combined with flow cytometry analysis of platelets taken directly from the cuvette offers the possibility to directly correlate the dynamics of platelet shape change and aggregation with the activity of established intracellular signaling pathways. The complexity of the underlying mechanisms and their wiring entails the inability to discern different signaling pathways. Defects or absence of signaling components may be obscured by others or compensated for by alternative pathways. Additionally, sample properties or composition significantly affect the aggregation response. While common aggregometry techniques (LTA as well as impedance aggregometry) require the formation of visible (macro-) aggregates, only micro-aggregates composed of only a small number of platelets are required in LaSca. This is due to the fundamentally different design of the detection method applied by LaSca. While LTA is based on multiple scattering by platelets, LaSca detects single scattering events. The theoretical basis of single scattering is more elaborate than of multiple scattering and allows the combined analysis of cell size, volume, and distribution together with shape change and aggregation. In addition, the sensitivity of the LaSca method is considerably increased due to the fact that the scattered light is observed against a virtually dark background. The LaSca method avoids the limitations of common aggregometry by using a standardized sample buffer hence providing a uniform and identical environment in all experiments. The contribution of concomitant plasma factors as well as secondary effects resulting from paracrine platelet action or platelet-platelet interaction is almost completely 
A

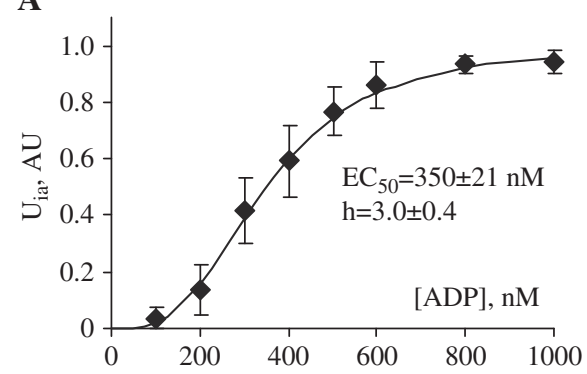

B

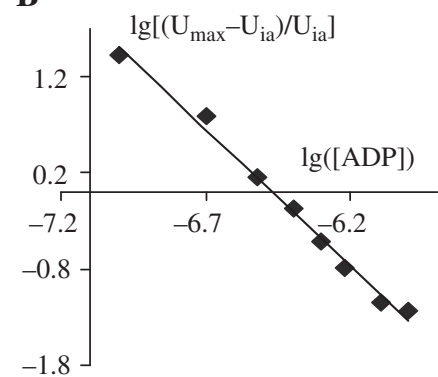

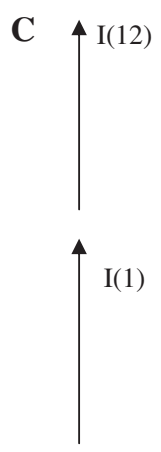

$1000 \mathrm{nM}$ ADP

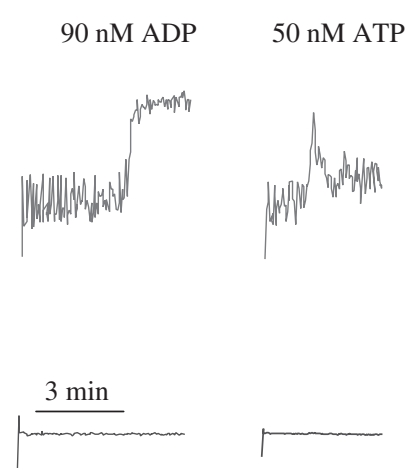

Figure 6 Application of the LaSca method to the investigation of mouse platelets.

Diluted mouse PRP $(10,000$ platelets $/ \mu \mathrm{L})$ was analyzed for the same parameters of ADP-induced aggregation as for human platelets (compare Figure 6A, 6B with Figure 2C, 2D). $\mathrm{EC}_{50}(350 \pm 21, \mathrm{n}=12)$ and Hill coefficient $(3.0 \pm 04, \mathrm{n}=12)$ values for mouse platelets are significantly $(\mathrm{p}<0.05)$ higher compared to human platelets. (C) Original recordings (representative for four independent experiments) of mouse platelet shape change I(12) and aggregation I(1) induced by $1 \mu \mathrm{M}$ and $90 \mathrm{nM}$ of ADP and $50 \mathrm{nM}$ of ATP are shown. $1 \mu \mathrm{M}$ ADP in mouse platelets, like in human platelets (compare with Figure 2C), induces a maximal aggregation response. The shape change reaction induced by $90 \mathrm{nM}$ ADP and $40 \mathrm{nM}$ ATP is also similar to human platelets (compare with Figure 4).

eliminated by dilution of the plasma. The LaSca method thus provides an opportunity to investigate distinct pathways and their respective role in platelet aggregation and shape change. Thus, the LaSca method enables detailed investigation of platelet responses to stimulating or inhibiting signals with clear distinction of shape change and aggregation. The pharmacological data obtained by LaSca underline the remarkable sensitivity of this technique compared to conventional aggregometry or other established methods. The improved sensitivity is not only advantageous with regard to pharmacological analysis but may also allow the identification and characterization of mild platelet disorders which are undetectable with standard laboratory techniques. Furthermore, anti-aggregatory drug action and efficacy can be quantified, and inadequate patient response to medication is detectable with high sensitivity. During development, dose finding and clinical phases for anti-platelet drugs there is undoubtedly a need for a meaningful functional parameter reflecting platelet responsivity. Likewise, a method for detection of unwanted platelet affecting action as a drug side effect with adequate sensitivity is required. For both applications the LaSca method is highly suitable and recommendable owing to its high sensitivity.

It has been recently recognized that the spectrum of platelet receptors and functional defects associated with bleeding disorders is significantly greater than previously established. Therefore, a diagnostic work-up and risk stratification of these patients would clearly benefit from cell function tests with increased accuracy and capable of phenotypic profiling (32). Monitoring of anti-platelet treatment has been recognized superior to genotyping for receptor or drug metabolism defects. Insufficient platelet inhibition has been shown to be correlated with an increased risk of recurrent cardiovascular events and fatal incidents during intervention. For instance, the frequently used anti-platelet drugs acetyl-salicylic acid and clopidogrel show considerable inter-individual variability in efficacy. Therapy failure is frequently associated with a high risk for adverse events, indicating the necessity for drug monitoring in order to improve the clinical outcome (33-37).

In summary, low angle light scattering analysis of human platelets as presented allows i)very sensitive and simultaneous quantitative online registration of changes in cell shape and aggregate formation; ii) highly improved sensitivity to detect agonist-evoked changes in human and mouse platelet shape change and aggregation, when compared to other methods including Born aggregometry; iii) quantitative functional analysis of various membrane receptors of human and mouse platelets and other cells which allow the phenotypic analysis of receptor defects and/or receptor inhibition in human diseases and mouse disease models. 
Responder

A

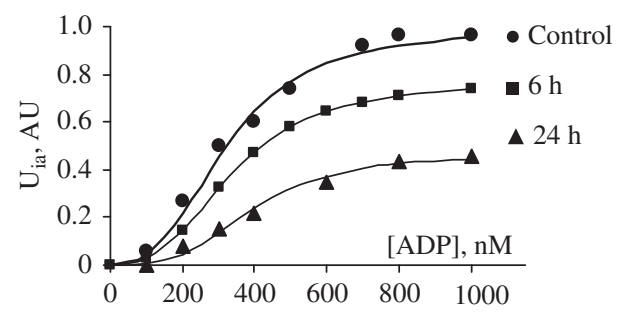

Non-responder

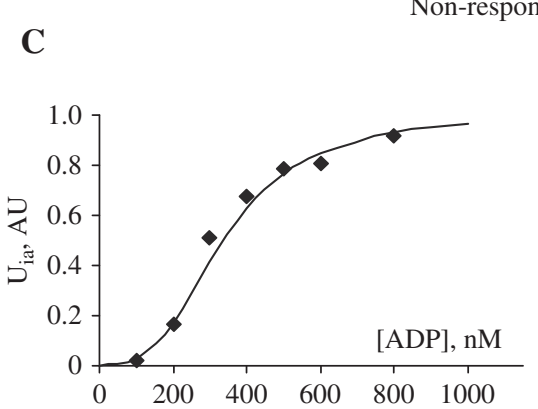

B

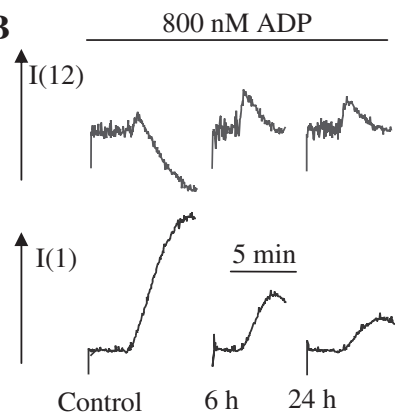

D

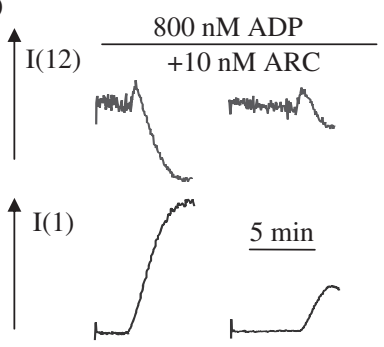

Figure 7 Application of the LaSca method to the investigation of ADP-induced platelet aggregation of a clopidogrel responder and a nonresponder.

(A, B) PRP from a healthy volunteer was analyzed before (control) and after $6 \mathrm{~h}$ and $24 \mathrm{~h}$ of single clopidogrel dose (600 $\mathrm{mg}$ ) (responder), and (C, D) $24 \mathrm{~h}$ after the same dose of clopidogrel (non-responder). In the clopidogrel responder the effect observed is similar to in vitro inhibition of the $\mathrm{P} 2 \mathrm{Y}_{12}$ receptor (compare with Figure 3B). (B) Original recording of platelet shape change and aggregation induced by $800 \mathrm{nM}$ ADP for the same time interval. Platelet aggregation parameters of the non-responder are similar to control (compare with Figure 3). (D) Original recording of platelet shape change and aggregation induced by $800 \mathrm{nM}$ ADP. In vitro application of AR-C69931 (10 nM) to non-responder indicates that the $\mathrm{P} 2 \mathrm{Y}_{12}$ receptor is functionally intact.

\section{Acknowledgments}

This work was supported by the DFG (Grants SFB 688, TP A2) and BMBF (Grant MedSys project 315395D). We thank A. Poltavcev and $\mathrm{V}$. Ostashev for help in designing the software and construction of the device.

\section{Conflict of interest statement}

Authors' conflict of interest disclosure: The authors stated that there are no conflicts of interest regarding the publication of this article. Research support played no role in the study design; in the collection, analysis, and interpretation of data; in the writing of the report; or in the decision to submit the report for publication.

Research funding: None declared.

Employment or leadership: None declared.

Honorarium: None declared.

\section{References}

1. Ruggeri ZM. Platelets in atherothrombosis. Nat Med 2002;8: 1227-34.

2. Ruggeri ZM, Mendolicchio GL. Adhesion mechanisms in platelet function. Circ Res 2007;100:1673-85.

3. Gawaz M. Platelets in the onset of atherosclerosis. Blood Cells Mol Dis 2006;36:206-10.
4. Linden MD, Jackson DE. Platelets: pleiotropic roles in atherogenesis and atherothrombosis. Int J Biochem Cell Biol 2010;42:1762-6.

5. Trip MD, Cats VM, van Capelle FJ, Vreeken J. Platelet hyperreactivity and prognosis in survivors of myocardial infarction. N Engl J Med 1990;322:1549-54.

6. Nesbitt WS, Westein E, Tovar-Lopez FJ, Tolouei E, Mitchell $\mathrm{A}, \mathrm{Fu} \mathrm{J}$, et al. A shear gradient-dependent platelet aggregation mechanism drives thrombus formation. Nat Med 2009;15: 665-73.

7. Pakala R, Waksman R. Currently available methods for platelet function analysis: advantages and disadvantages. Cardiovasc Revasc Med 2011;12:312-22.

8. Born GV, Cross MJ. The aggregation of blood platelets. J Physiol 1963;168:178-95.

9. Spurej E, Glatter O, Pfeiler G. Shape change of human blood platelets: reliable and fast detection by quasi-elastic light scattering. Experientia 1992;48:71-9.

10. Abela GS, Huang R, Ma H, Prieto AR, Lei M, Schmaier AH, et al. Laser-light scattering, a new method for continuous monitoring of platelet activation in circulating fluid. J Lab Clin Med 2003;141:50-7.

11. Ingerman-Wojenski C, Smith JB, Silver MJ. Evaluation of electrical aggregometry: comparison with optical aggregometry, secretion of ATP, and accumulation of radiolabeled platelets. J Lab Clin Med 1983;101:44-52.

12. Kobsar AL, Koessler J, Rajkovic MS, Brunner KP, Steigerwald U, Walter U. Prostacyclin receptor stimulation facilitates detection 
of human platelet $\mathrm{P} 2 \mathrm{Y}_{(12)}$ receptor inhibition by the PFA-100 system. Platelets 2010;21:112-6.

13. Gambaryan S, Geiger J, Schwarz UR, Butt E, Begonja A, Obergfell A, et al. Potent inhibition of human platelets by cGMP analogs independent of cGMP-dependent protein kinase. Blood 2004;103:2593-600.

14. Gruner S, Prostredna M, Aktas B, Moers A, Schulte V, Krieg T, et al. Anti-glycoprotein VI treatment severely compromises hemostasis in mice with reduced $\alpha 2 \beta 1$ levels or concomitant aspirin therapy. Circulation 2004;110:2946-51.

15. Latimer P. Blood platelet aggregometer: predicted effects of aggregation, photometer geometry, and multiple scattering. Appl Opt 1983;22:1136-43.

16. Hulst VD. Light scattering by small particles. New York: John Willey \& Sons, 1957.

17. Daniel JL, Dangelmaier C, Jin J, Ashby B, Smith JB, Kunapuli SP. Molecular basis for ADP-induced platelet activation. I. Evidence for three distinct ADP receptors on human platelets. J Biol Chem 1998;273:2024-9.

18. Hechler B, Cattaneo M, Gachet C. The P2 receptors in platelet function. Semin Thromb Hemost 2005;31:150-61.

19. Gachet C. Regulation of platelet functions by P2 receptors. Annu Rev Pharmacol Toxicol 2006;46:277-300.

20. Kim S, Kunapuli SP. P2Y receptor in platelet activation. Platelets 2011;22:54-8.

21. Hechler B, Leon C, Vial C, Vigne P, Frelin C, Cazenave JP, et al. The $\mathrm{P} 2 \mathrm{Y}_{1}$ receptor is necessary for adenosine $5^{\prime}$-diphosphateinduced platelet aggregation. Blood 1998;92:152-9.

22. Fabre JE, Nguyen M, Latour A, Keifer JA, Audoly LP, Coffman $\mathrm{TM}$, et al. Decreased platelet aggregation, increased bleeding time and resistance to thromboembolism in $\mathrm{P}_{2} \mathrm{Y}_{1}$-deficient mice. Nat Med 1999;5:1199-202.

23. Leon C, Hechler B, Freund M, Eckly A, Vial C, Ohlmann P, et al. Defective platelet aggregation and increased resistance to thrombosis in purinergic $\mathrm{P} 2 \mathrm{Y}_{(1)}$ receptor-null mice. J Clin Invest 1999;104:1731-7.

24. Andre P, Delaney SM, LaRocca T, Vincent D, DeGuzman F, Jurek $\mathrm{M}$, et al. $\mathrm{P} 2 \mathrm{Y}_{12}$ regulates platelet adhesion/activation, thrombus growth, and thrombus stability in injured arteries. J Clin Invest 2003; $112: 398-406$

25. Mahaut-Smith MP, Ennion SJ, Rolf MG, Evans RJ. ADP is not an agonist at $\mathrm{P} 2 \mathrm{X}_{(1)}$ receptors: evidence for separate receptors stimulated by ATP and ADP on human platelets. Br J Pharmacol 2000;131:108-14.

26. Fung CY, Cendana C, Farndale RW, Mahaut-Smith MP. Primary and secondary agonists can use $\mathrm{P} 2 \mathrm{X}_{(1)}$ receptors as a major pathway to increase intracellular $\mathrm{Ca}\left(2^{+}\right)$in the human platelet. J Thromb Haemost 2007;5:910-7.

27. Mahaut-Smith MP, Tolhurst G, Evans RJ. Emerging roles for P2X receptors in platelet activation. Platelets 2004;15:131-44.

28. Erhardt JA, Pillarisetti K, Toomey JR. Potentiation of platelet activation through the stimulation of $\mathrm{P}_{2} \mathrm{X}_{1}$ receptors. $\mathrm{J}$ Thromb Haemost 2003;1:2626-35.

29. Rolf MG, Mahaut-Smith MP. Effects of enhanced P2X receptor $\mathrm{Ca} 2^{+}$influx on functional responses in human platelets. Thromb Haemost 2002;88:495-502.

30. Rettinger J, Schmalzing G. Activation and desensitization of the recombinant $\mathrm{P}_{2} \mathrm{X}_{1}$ receptor at nanomolar ATP concentrations. J Gen Physiol 2003;121:451-61.

31. North RA. Molecular physiology of P2X receptors. Physiol Rev 2002;82:1013-67.

32. Watson S, Daly M, Dawood B, Gissen P, Makris M, Mundell S, et al. Phenotypic approaches to gene mapping in platelet function disorders - identification of new variant of P2 $\mathrm{Y}_{12}$, TxA2 and GPVI receptors. Hamostaseologie 2010;30:29-38.

33. Beigel R, Hod H, Fefer P, Asher E, Novikov I, Shenkman B, et al. Relation of aspirin failure to clinical outcome and to platelet response to aspirin in patients with acute myocardial infarction. Am J Cardiol 107:339-42.

34. Sofi F, Marcucci R, Gori AM, Abbate R, Gensini GF. Residual platelet reactivity on aspirin therapy and recurrent cardiovascular events - a meta-analysis. Int J Cardiol 2008;128:166-71.

35. Schuhmann CG, Sohn HY, Nagel J, Spannagl M, Klauss V, Krotz F. Clinical management of clopidogrel inefficiency by point of care platelet function testing and individual adjustment of anti-platelet therapy - initial experiences. Platelets 2009;20:498-504.

36. Frelinger AL, 3rd, Li Y, Linden MD, Barnard MR, Fox ML, Christie DJ, et al. Association of cyclooxygenase-1-dependent and -independent platelet function assays with adverse clinical outcomes in aspirin-treated patients presenting for cardiac catheterization. Circulation 2009;120:2586-96.

37. Patrono C. The $\mathrm{P} 2 \mathrm{Y}_{12}$ receptor: no active metabolite, no party. Nat Rev Cardiol 2009;6:271-2. 